\title{
Herpes simples recorrente na prática ortodôntica: devemos suspender o atendimento?
}

\author{
Alberto Consolaro* e Maria Fernanda M-O. Consolaro**
}

No dia a dia clínico, as doenças mais comuns da mucosa bucal atrapalham o andamento dos tratamentos odontológicos, pois:

1. podem requerer o adiamento de sessões, em função da possibilidade de contágio;

2. promovem desconforto para o paciente;

3. geram limitações das manobras clínicas por parte do profissional;

4. exigem proteção adicional de biossegurança; e

5. requerem diagnóstico e prognóstico precisos a partir de uma terapêtica adequada.

O pronto diagnóstico seguido pela tomada de decisões por parte do clínico economiza tempo, propicia biossegurança ao paciente, profissional, auxiliares e demais pacientes, ao mesmo tempo que demonstra domínio profissional sobre o assunto, agregando valor à sua atividade específica dentro da Odontologia.

Dentre as doenças mais comuns da mucosa bucal que podem ser enquadradas nesse contexto têm-se: herpes simples, aftas bucais, mucoceles, papilomas e lesões reacionais como as hiperplasias fibrosas inflamatórias, granuloma piogênico, fibroma odontogênico periférico e lesões periféricas de células gigantes.

Excluindo-se as infecções respiratórias, o herpes simples representa a doença viral mais comum no homem moderno. Embora possa, inicialmente, ser aguda, os quadros crônicos da doença se estabelecem com muita frequência. O homem, como hospedeiro natural do Herpesvirus hominis $(\mathrm{HVH})$, apresenta várias manifestações recorrentes ou secundárias da doença em períodos intercalados de tempo. Em pacientes imunocomprometidos, as infecções herpéticas podem provocar severas complicações ${ }^{8}$. O herpes simples também é classificado como DST, ou doença sexualmente transmissivel.

Os profissionais são frequentemente questionados pelos pacientes sobre o diagnóstico, tratamento e cuidados relacionados ao herpes simples recorrente. As lesões recorrentes do herpes simples são altamente contagiosas para os pacientes, suas famílias, profissionais da saúde e auxiliares ${ }^{19}$. Muitas dúvidas e questionamentos são feitos sobre o assunto, especialmente se durante a presença das lesões recorrentes o profissional deve submeter o paciente ao tratamento odontológico previamente planejado ou adiar a sessão para quando as mesmas desaparecerem. Para contribuir com o esclarecimento, propusemo-nos a discorrer sobre esse assunto e induzir novos questionamentos e reflexões sobre o herpes simples, em especial o herpes simples recorrente na mucosa bucal e suas implicações na prática clínica ortodôntica.

\footnotetext{
* Professor Titular de Patologia - USP.

** Professora doutora de Ortodontia e Biologia Oral - USC.
} 


\section{FREQUÊNCIA, TECIDOS COMPROMETIDOS E CLASSIFICAÇÃO VIRAL}

O herpes simples afeta milhares de pessoas em todas as regiões do mundo. Em condições urbanas e superpovoadas, praticamente todas as pessoas foram expostas ao $\mathrm{HVH}$, se considerarmos que:

a) Em $100 \%$ das crianças acima de cinco anos de idade são encontrados anticorpos circulantes contra o HVH, ou seja, essas já entraram em contato com o vírus.

b) A marca representada pelos anticorpos circulantes ainda está presente em 50\% dos adultos.

c) Da população adulta geral, $80-90 \%$ das pessoas foram expostas ao $\mathrm{HVH}^{2,8,14,18,20,21,23}$.

d) Entre 40 e $75 \%$ dos adultos apresentam lesões herpéticas recorrentes.

Entretanto, curiosamente, no Japão e nos países escandinavos, a prevalência do herpes simples é uma das mais baixas do mundo, em torno de $48 \%$, contrastando com as demais regiões do mundo, em média com 90\% de comprometimento pelo $\mathrm{HVH}$. Pode ser que a restrição cultural ao contato pessoal e social, menos frequente nessas populações, ajude a explicar esses dados.

O HVH infecta os tecidos neuroectodérmicos e, assim, parasita os epitélios de revestimento, células neurais como os nervos periféricos e sistema nervoso central, bem como as meninges e, mais raramente, os epitélios internos do organismo.

O HVH pode ser classificado, inicialmente, em:

a) Tipo 1 e indutor de quadros clínicos extragenitais, especialmente a parte superior do corpo, principalmente a pele, mucosas bucal, orofaríngea e conjuntiva, gânglio trigeminal e sistema nervoso central.

b) Tipo 2 e indutor de quadros clínicos genitais e perigenitais e demais regiões inferiores do corpo, como a pele e gânglios sacrais.

Essa classificação topográfica do herpes simples e tipo viral deve ser relativizada, pois, em um terço das mulheres americanas com a forma genital da doença, essa foi induzida por HVH tipo $1^{13}$.
Em certas populações amazônicas, o HVH-1 foi o indutor de ulcerações genitais em 28,5\% dos pacientes, e na Inglaterra essa prevalência chega a $50 \%{ }^{15}$. Da mesma forma, não há esta divisão em lesões exclusivamente de pele.

\section{HERPESVIRUS HOMINIS: SUA ESTRUTURA E CAPACIDADE DE INFECÇÃO}

O HVH tem sua estrutura constituída por $7 \%$ de DNA, 69\% de proteínas, 22\% de fosfolipídeos e $2 \%$ de carboidratos, distribuídos em suas estruturas básicas: o genoma, o capsídeo, o tegumento e o envelope. O HVH-1 e 2 diferem em 50\% no DNA. Os testes laboratoriais revelam relação de semelhança entre ambos, mas não de igualdade, assim são vírus com identidades estruturais diferentes.

O genoma do $\mathrm{HVH}$ é constituído por filamento duplo de DNA envolto por uma membrana proteica denominada capsídeo e formada por 162 unidades estruturais ou capsômeros. O genoma envolvido pelo capsídeo forma um conjunto

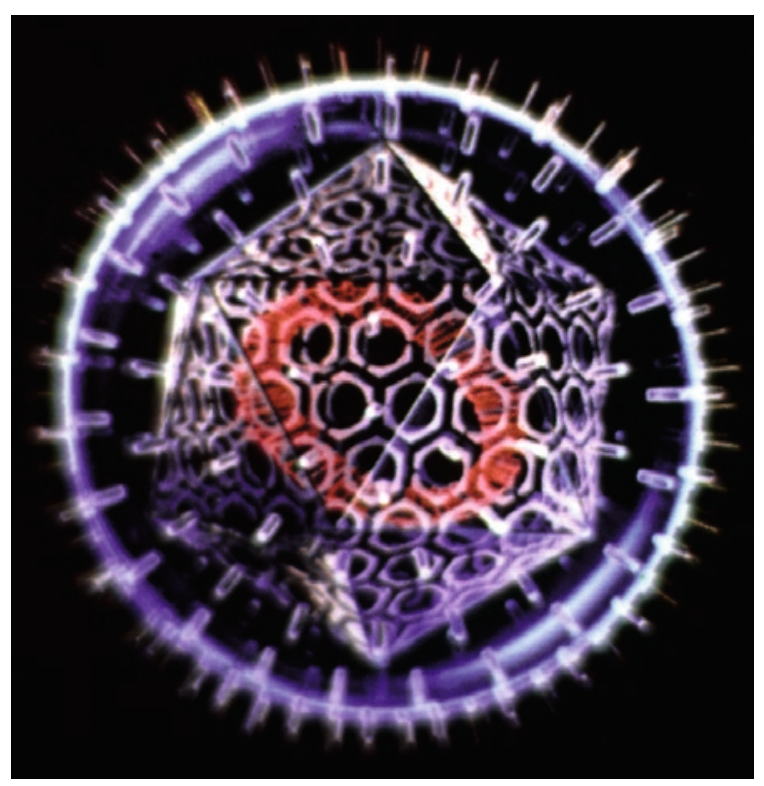

FIGURA 1 - Herpesvirus hominis: filamento duplo de DNA, em vermelho, dentro do capsídeo multifacetado. 0 envelope, a parte mais externa, tem numerosas glicoproteínas em forma de espinhos. Entre o capsídeo e 0 envelope tem-se o tegumento. A partícula viral tem, em média, de 150 a 200 nanômetros de diâmetro, ou seja 0,000012 a 0,000020 milímetro. 
identificado como nucleocapsídeo, com uma forma esférica de 100 nanômetros de diâmetro.

Envolvendo externamente o nucleocapsídeo tem-se uma segunda membrana denominada envelope, com duas camadas de lipídeos com glicoproteínas embebidas no seu interior e, provavelmente, derivadas das membranas das células parasitadas. Entre a membrana mais interna ou capsídeo e a mais externa tem-se um preenchimento proteináceo chamado tegumento. $\mathrm{O}$ vírus, como um todo, forma uma esfera com 120 a 200 nanômetros de diâmetro ${ }^{8,11,24}$, ou seja 0,000012 a 0,000020 milímetro. O componente lipídico provavelmente explica a sensibilidade do $\mathrm{HVH}$ em culturas frente aos solventes lipídicos como o éter, por exemplo.

Vários fatores interferem na infectividade do $\mathrm{HVH}$, um vírus estável particularmente na presença de proteínas. Por algumas horas, a $37^{\circ} \mathrm{C}$, o $\mathrm{HVH}$ continua infeccioso, mas a $39^{\circ} \mathrm{C}$ deixa de produzir DNA e proteínas do envelope. Esse vírus é sensivel ao calor e à ação direta de ácidos com $\mathrm{pH}$ inferior a 6,8, éter, solventes lipídicos, detergentes catiônicos, enzimas proteolíticas, aldeídos, fenol e radiação ultravioleta.

\section{CONTÁGIO E PENETRAÇÃO VIRAL NO ORGANISMO}

O HVH está no meio ambiente a partir de sua liberação das lesões herpéticas primárias e recorrentes nos portadores da doença, especialmente a partir do rompimento de vesículas e bolhas que caracterizam sua manifestação clínica. O HVH pode, ainda, ser encontrado na garganta, secreções e fezes. O HVH pode sobreviver horas ou dias no meio externo, desde que haja presença de proteínas, como no pus, restos necróticos e sangue.

Algumas pessoas têm manifestações subclínicas da doença, justificando porque de 2 a $5 \%$ das pessoas aparentemente normais têm vírus em sua saliva $^{5}$, tal como ocorre com $20 \%$ das crianças entre 7 meses e 2 anos de idade ${ }^{3,7}$.

O contágio quase sempre ocorre por contatos pessoais como beijos, relações sexuais ou objetos contaminados. O contágio profissional em dentistas, médicos e pessoal auxiliar pode ocorrer em consultórios e hospitais. O herpes simples primário é muito mais comum em profissionais da saúde. O herpes cutâneo, mais comumente na forma de eczema herpético, desenvolve-se em locais da pele com lesões preexistentes, como traumatismos, urticária, alergias, etc.

Há um período médio de incubação de 7 dias, variando de 1 a 26 dias. Nas manifestações primárias do herpes simples, a liberação de vírus permanece por 15 a 42 dias.

$\mathrm{O} \mathrm{HVH}$ não tem capacidade de penetração em epitélios queratinizados e precisa entrar em contato com células epiteliais vivas. A sua entrada ocorre, principalmente, nas mucosas não queratinizadas - como em algumas regiões bucais, genitais e oftálmicas. Na pele e outros epitélios queratinizados, a entrada do $\mathrm{HVH}$ se dá principalmente nas áreas traumatizadas, escoriadas e com queimaduras, nas quais as células epiteliais vivas ficam expostas ao meio ambiente, sem recobrimento da camada córnea.

Quando o paciente é portador de uma lesão herpética vesicular no lábio, por exemplo,

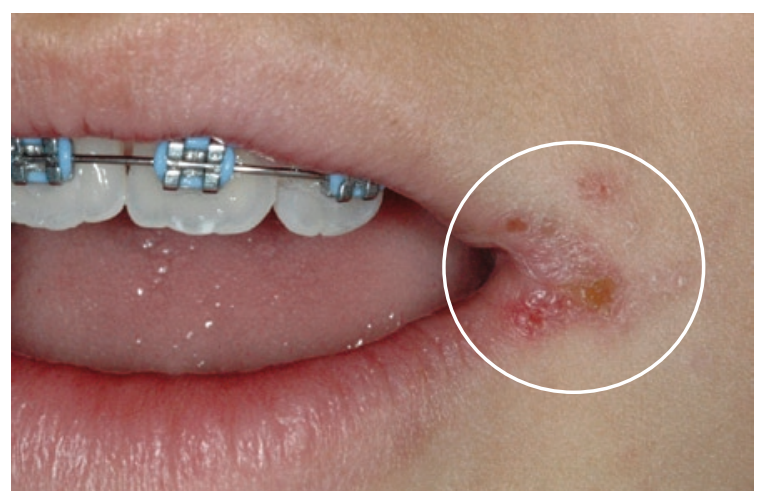

FIGURA 2 - Herpes simples recorrente labial. Durante os procedimentos ortodônticos, pode ocorrer dilaceração dos tecidos afetados, com ruptura das vesículas, derramamento de seu conteúdo contaminado, sangramento e desconforto com dor. As manobras clínicas podem ser limitadas pela presença da lesão, o que justifica o adiamento da sessão clínica, além das implicações relacionadas com a biossegurança. 0 paciente deve ser orientado sobre as implicações biológicas, sociais e clínicas da doença. 


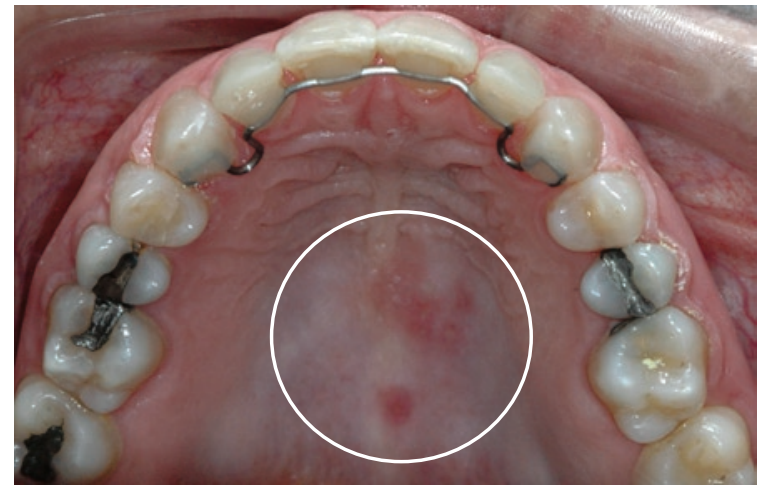

FIGURA 3 - Frequentemente, o episódio recorrente do herpes simples no palato duro não é diagnosticado durante os procedimentos ortodônticos e pode ter implicações relacionadas com a biossegurança do paciente, profissional e auxiliares. 0 palato duro é a região intrabucal mais comprometida pelo herpes simples recorrente. 0s pacientes acreditam que essas lesões herpéticas recorrentes no palato duro decorrem de traumatismos por alimentos ou escovação dentária.

e a manipula com os dedos, levando-os a outras áreas do corpo, pode-se inocular o vírus em uma nova região e lesões se estabelecerem, com frequência, agora nesse novo local. Esse processo, também denominado autoinoculação, é muito importante, pois pode explicar porque pacientes com lesões labiais podem, com o tempo, apresentar ainda lesões cutâneas, genitais e oftálmicas. Vice-versa também pode ocorrer em relação ao lábio. A autoinoculação foi experimentalmente comprovada ${ }^{12}$.

Estima-se que de 10 a $20 \%$ dos pacientes infectados se definam como portadores de herpes simples. Até $60 \%$ dos indivíduos soropositivos para $\mathrm{HVH}$ apresentam quadros assintomáticos ou subclínicos não reconhecidos pelos próprios pacientes como herpes simples ${ }^{22}$. Essa avaliação ajuda-nos a entender porque a disseminação da doença é tão grande na população. Muitos casos de herpes simples são diagnosticados equivocadamente como estados gripais, aftas e infecções genitais inespecíficas ${ }^{14}$.

A contaminação durante a passagem do feto pelo canal vaginal, em mães infectadas, pode provocar o herpes genital neonatal - do $3^{\circ}$ ao $8^{\circ}$ dia após o nascimento -, que é fatal em $70 \%$ dos casos.
Os pacientes que sobrevivem apresentam sérios comprometimentos do sistema nervoso central. O herpes neonatal raramente é adquirido na fase intrauterina por via transplacentária, representando aproximadamente $10 \%$ dos casos.

\section{CICLO CELULAR DO HVH}

A penetração viral determina modificações bioquímicas funcionais e estruturais nas células infectadas para ocorrer a reduplicação e multiplicação viral, caracterizando um ciclo celular com fases distintas: adsorção, penetração, eclipse, síntese, acoplamento e liberação.

Adsorção: o contato do vírus com a célula hospedeira ocorre por colisão acidental, formando uma ligação inicialmente fraca e posteriormente estável. Na superfície da célula hospedeira existem receptores específicos, isto é, regiões com configuração bioquímica compatível com a partícula viral, porém indistinguíveis morfologicamente.

A união do vírus com a membrana celular depende da presença de certos íons no meio extracelular, de seus efeitos na superfície e da carga eletrostática do envelope viral. A glicoproteína viral gC ou gB liga-se na superfície celular a partir da proteoglicana de heparan sulfato. Posteriormente, a gD liga-se a vários receptores da superfície celular e promove a fusão do envelope à membrana celular ${ }^{1,2}$.

Penetração: inicia-se com a fusão do envelope e da membrana celular, liberando o nucleocapsídeo para dentro do citoplasma. Eventualmente, também pode ocorrer a penetração viral por fagocitose em vesículas pinocitóticas, liberando-se o nucleocapsídeo dentro de um vacúolo, por digestão enzimática do envelope.

Eclipse: esta fase caracteriza-se pela perda dos dois invólucros ou membranas virais. Após a penetração viral, as enzimas celulares degradam os remanescentes do envelope no citoplasma e expõem o capsídeo da partícula viral, que migra em direção ao núcleo, assumindo posição próxima aos poros nucleares. Essa membrana mais interna da 
partícula viral, ou capsídeo, também é degradada pelas enzimas celulares e o genoma representado pelo filamento duplo de DNA entra no núcleo atravessando seus poros.

Síntese: simultaneamente ao eclipse, iniciamse as modificações no metabolismo celular. O genoma viral, agora incorporado no genoma celular, programa toda a célula para que seu metabolismo desencadeie o processo bioquímico de formação de moléculas para constituírem novas partículas virais. Praticamente toda a maquinaria celular será acionada para que as enzimas construam novos filamentos duplos de DNA, proteínas e outras subunidades virais estruturais. Ao mesmo tempo, as enzimas bloqueiam a mitose celular. Nos neurônios, essas atividades não parecem ser executadas, pois não entram normalmente em mitose. Dessa forma, o HVH pode ficar imunologicamente invisível no interior dos neurônios, ou seja, em estado de latência.

Acoplamento: as proteínas estruturais virais são carreadas para o núcleo e participam do processo de montagem ou acoplamento das partes do filamento duplo do DNA viral. Ainda no núcleo, o DNA viral é envolvido pelas proteínas do capsídeo, também denominadas capsômeros. Ainda no núcleo celular, o nucleocapsídeo viral, formado pelo genoma envolto no capsídeo, começa a ser envolvido por proteínas ao passar pela membrana nuclear para formar o seu envoltório mais externo do vírus ou envelope.

Liberação: os vírus no citoplasma alcançam o exterior da célula por meio de túbulos membranosos que atravessam o citoplasma e comunicamse com o exterior. Os vírus podem, ainda, ser lançados ao exterior por um processo semelhante à fagocitose reversa. Ao passar pela membrana celular, os vírus deixam algumas glicoproteínas e isso pode ser marcador para uma reação imunológica contra as mesmas.

Sincronizadamente, cada célula hospedeira forma milhões de novos vírus até seu esgotamento metabólico e necrose.

\section{EFEITOS CELULARES E TECIDUAIS DO HVH}

No ciclo viral ocorrem mudanças e danos às células hospedeiras denominados efeitos citopatogênicos e, juntamente com a invasão viral, desencadeiam respostas orgânicas defensivas.

A erupção de vesículas intraepiteliais após um período prodrômico de 12 horas resulta do edema intracelular, ou "degeneração" balonizante, com rompimento das células locais e acentuada acantólise. Esse efeito balonizante do edema intracelular resulta do acúmulo de água nas organelas e nas células provocado pelas alterações estruturais e funcionais nas suas membranas.

Inicialmente, as células epiteliais comprometidas e tumefatas estão limitadas ao epitélio, mas gradativamente as células basais também são afetadas e a vesícula/bolha, inicialmente intraepitelial, passa a acumular líquidos em sua interface com o tecido conjuntivo e assume uma posição subepitelial. Dessa forma, milhões de vírus entram em contato com os filetes nervosos do tecido conjuntivo subjacente às lesões, contaminando-os, na manifestação primária, e recontaminando-os nas recorrências. Após o rompimento das vesículas e bolhas, o tecido conjuntivo fica exposto ou ulcerado ao meio externo.

$\mathrm{Na}$ exposição primária ou na reativação do $\mathrm{HVH}$ latente no tecido neural, as proteínas livres originárias das células mortas e dos vírus - juntamente com os numerosos mediadores presentes nas vesículas e bolhas subepiteliais - induzem pronunciada vasodilatação e fragilidade capilar decorrente de invasão viral das células endoteliais. A infiltração de células inflamatórias, especialmente polimorfonucleares, e a intensa exsudação plasmática serosa ocorrem e contribuem para a ampliação das vesículas e bolhas. Essas alterações teciduais explicam as alterações na sensibilidade local, o eritema e o edema da área que caracterizam as manifestações clínicas precoces da doença.

Os corpúsculos de inclusão intranuclear nas células infectadas pelo HVH-l correspondem ao acúmulo de proteínas virais específicas resultantes 


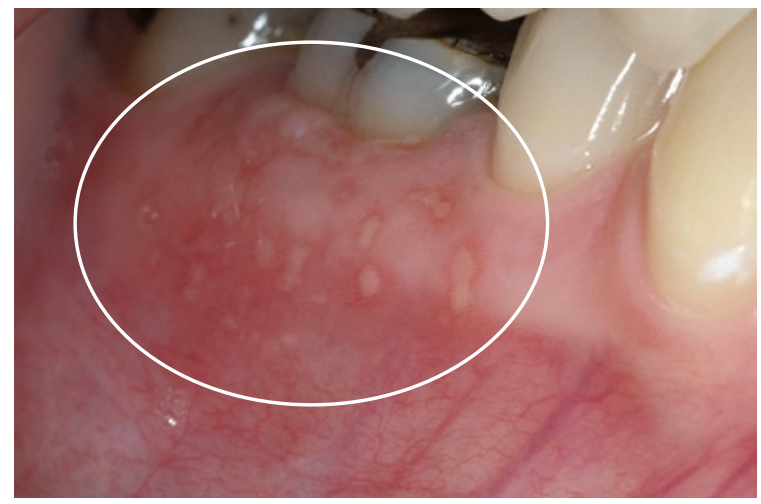

FIGURA 4 - Herpes simples recorrente gengival: com frequência, a manifestação é diagnosticada como lesão traumática, química ou alérgica. A gengiva representa o segundo lugar mais frequente de herpes simples recorrente intrabucal.

da síntese e formação do genoma e do capsídeo. Inicialmente, esses corpúsculos são basofílicos, mas tornam-se eosinofílicos assim que ocorre a migração dos nucleocapsídeos para o citoplasma. Foram descritos, em 1934 por Cowdry $^{6}$, como do tipo A. Essas inclusões nucleares, próprias do $\mathrm{HVH}$, também são conhecidas como corpúsculos de Lipschutz.

Outro efeito citopatogênico consiste na formação de células gigantes multinucleadas por coalescência de células epiteliais, mas de natureza sincicial, para dificultar a ação de anticorpos sobre as células parasitadas, protegendo os vírus neoformados nas células mais centrais. Essas células gigantes multinucleadas são também referidas nas lesões herpéticas como células de Tzanck.

\section{LATÊNCIA E RECORRÊNCIA}

Ao mesmo tempo que os fenômenos inflamatórios agudos da exposição primária, o organismo do hospedeiro desencadeia a resposta imunológica primária com formação de anticorpos neutralizantes de vida molecular efêmera, podendo ser necessária uma série de surtos recidivantes para manter o nível sérico elevado.

Os anticorpos não previnem a produção de antígenos virais ou vírus no interior das células epiteliais infectadas, mas quando em contato por longo tempo podem eliminar o HVH-1 em células degeneradas ou ao redor das células epiteliais. Com a lise das células infectadas, os anticorpos previnem a transmissão do HVH-1 em $86 \%$ para outras células vizinhas.

Uma vez estabelecida a resposta imunológica primária, a fase aguda desaparece em 1 a 3 semanas. Os vírus não eliminados, em parte, permanecem no interior das células basais do epitélio; a outra parte dos vírus contata as terminações nervosas no tecido conjuntivo e, através dos axônios, alcança o gânglio trigeminal, por um mecanismo desconhecido. Nas células basais e no gânglio trigeminal, permanecem em estado de latência, sem contato com o sistema imunológico.

O estado de latência do HVH-1, quando interrompido, resultará em recorrências do herpes simples na mesma região da penetração viral inicial. As partículas virais localizadas no gânglio trigeminal atingem a superfície mucosa e cutânea através dos axônios, por mecanismo reverso ainda não desvendado. A natureza, manutenção, duração e influências do estado de latência são ainda, inacreditavelmente, desconhecidas ${ }^{1,4}$.

A interrupção do estado de latência do HVH-1, em geral, está relacionada com fatores comuns à maioria dos pacientes, como febre, exposição ao sol e à radiação ultravioleta, estresse físico e/ou mental, distúrbios gastrintestinais, traumatismos mecânicos, gripes, resfriados, ansiedade, menstruação, gravidez e outros ${ }^{8,9}$. As recorrências ocorrem a partir dos 15 anos de idade, diminuindo sensivelmente após a terceira década de vida.

Alguns procedimentos odontológicos podem desencadear a quebra de latência viral, especialmente as exodontias. Diante do estresse psicológico representado - para alguns pacientes - pelo procedimento odontológico, compreende-se porque isso venha a ocorrer eventualmente.

Um fator muito importante na interrupção da latência viral do $\mathrm{HVH}$ é a diminuição da competência imunológica do hospedeiro, pois as 
recorrências são mais severas em pacientes imunodeprimidos, como os pacientes com AIDS, hemolinfopatias severas, transplantados e sob medicação imunodepressora. Nesses pacientes, a imunidade celular encontra-se muito comprometida. De alguma forma, os fatores relacionados às recorrências do herpes simples têm associação com a redução da capacidade imunológica.

\section{SUSPENDER O ATENDIMENTO: UMA QUESTÃO DE BIOSSEGURANÇA!}

Os pacientes portadores do herpes simples no lábio e na mucosa bucal interna que se apresentam para o tratamento odontológico com vesículas e bolhas preservadas têm no seu conteúdo milhões de vírus infectantes.

Ao romper uma vesícula, a agulha e a gaze utilizadas na perfuração devem ser descartadas como material contaminado. Na medida do possível, deve-se evitar que o líquido escorra para outras partes da mucosa e da pele, mesmo que em áreas imediatamente vizinhas. A autoinoculação em outras áreas já foi demonstrada experimentalmente.

Deve-se orientar o paciente a:

1. Não perfurar as vesículas sem um treinamento prévio. $\mathrm{O}$ rompimento precoce das vesículas e das bolhas parece acelerar o curso da doença, reduzindo sua duração, mas predispõe o local a infecções bacterianas secundárias. Quando primariamente herpéticas, as lesões não deixam cicatrizes, mas, quando infectadas, marcas temporárias ou permanentes podem se instalar.

2. Caso o paciente queira fazê-lo, deve-se orientá-lo que o líquido vesicular está contaminado com milhões de vírus e, ao contatar outras partes do corpo, pode fazer com que, no novo local, novas lesões herpéticas posteriores surjam, periodicamente, a partir deste fato. Os instrumentos utilizados na perfuração devem ser esterilizados, ou, no mínimo, desinfetados.

3. Mesmo sem a perfuração das lesões, a manipulação das lesões pode contaminar as mãos, que - se levadas aos olhos e outras mucosas - podem fazer com que o paciente com lesões labiais herpéticas recorrentes passe a ter herpes oftálmico, genital e/ou cutâneo.

A sessão clínica do tratamento deve ser adiada se não constituir uma urgência ou emergência ${ }^{19}$, pois - ao se manipular os tecidos moles durante procedimentos odontológicos - pode-se romper as vesículas e bolhas herpéticas, escorrendo o líquido para outras partes. Ao mesmo tempo, ocorrerá um aumento no risco de contaminação do profissional e pessoal auxiliar, além de instrumentos, sugadores, peças de mão, etc.

$\mathrm{Na}$ saliva de muitas pessoas saudáveis, mas portadoras, pode-se isolar o $\mathrm{HVH}$, mas o número de vírus deve ser consideravelmente menor do que em um paciente com lesões ativas de herpes simples recorrente. $\mathrm{Na}$ saliva de pessoas assintomáticas, o HVH-1 foi encontrado com muito maior facilidade do que o HVH-2 ${ }^{17}$. Em outras palavras, no spray e perdigotos gerados durante o tratamento odontológico, o $\mathrm{HVH}$ pode atingir o profissional e pessoal auxiliar, especialmente nos olhos e na pele traumatizada ou lesada, considerando-se que os mesmos estão utilizando máscaras protetoras adequadas. Da mesma forma, os moldes e modelos poderão estar contaminados e transladando o vírus para outras pessoas em sua manipulação e análise.

Quando as lesões herpéticas deixam o aspecto de vesículas e bolhas, e passam a ser lesões ulceradas e crostosas, ainda assim há risco aumentado considerável de contaminação por mais alguns dias. O herpes simples recorrente não deixa cicatrizes; o ideal seria retomar as sessões uma vez reparada a região afetada.

Mas há situações em que a intervenção do profissional se faz necessária, por vários motivos, mesmo com lesões herpéticas bucais. Nesse caso, deve-se tomar as medidas-padrão de assepsia, esterilização, desinfecção e antissepsia. O HVH sobrevive por algumas horas longe do organismo humano, mas para isso é necessária a presença de proteínas derivadas da saliva, sangue e outras secreções. 
Esses produtos podem permanecer residuais nas peças de mão, luvas, plásticos protetores, cadeiras, óculos e nas roupas do profissional, em função do spray e jatos de água, assim como nos moldes e modelos.

O HVH é pouco resistente ao calor e sensível a muitos produtos químicos já citados anteriormente. A capacidade de infectar e a resistência do HVH são incomparavelmente menores do que do vírus da hepatite B. Se tomadas todas as medidas necessárias de biossegurança, algumas especificamente mencionadas anteriormente, o risco de contaminação ainda assim existe, mas é reduzido, muito embora o ideal seja adiar a sessão, o que nem sempre é possível.

Além dos aspectos relacionados à biossegurança, o paciente com lesões herpéticas tem desconforto com dor e prurido na região, sangramento facial e ruptura vesicular durante as manipulações dos tecidos moles envolvidos, inevitáveis durante as manobras clínicas necessárias.

Por fim, se o paciente tem a intenção de se livrar das recorrências do herpes simples na boca, esse objetivo pode ser alcançado. Para isso, o tratamento deve ser instituído em todas as recorrências e no seu período prodrômico $0^{9,10}$. A cada tratamento de cada uma das recorrências, o número de partículas virais tende a diminuir, gradativamente, nos tecidos e células do hospedeiro.

Para fundamentar esse tipo de tratamento e outras formas terapêuticas, se faz necessário detalharmos sobre as formas clínicas do herpes simples, as variações e nuanças em suas manifestações na boca para um diagnóstico preciso e precoce ${ }^{16}$. Em um próximo trabalho continuaremos a discorrer sobre o herpes simples, especialmente sobre como diagnosticar corretamente essa doença e sua forma mais atual e eficiente de tratamento.

O pronto diagnóstico seguido pela tomada de decisões por parte do clínico economiza tempo, propicia biossegurança ao paciente, profissional, auxiliares e demais pacientes, ao mesmo tempo que demonstra domínio profissional sobre o assunto, agregando valor à sua atividade específica dentro da Odontologia.

\section{CONSIDERAÇÃO FINAL: REFLEXÕES E SUGESTÕES}

Suspender o atendimento clínico ortodôntico quando o paciente apresenta herpes simples recorrente na região peribucal e intrabucal atende aos preceitos de biossegurança para todos os envolvidos na atividade clínica, muito embora nem sempre isso possa ser seguido de forma absoluta.

Em Ortodontia, são raras as pesquisas clínicas sobre o herpes simples na prática da especialidade. Ainda faltam trabalhos na forma de publicações, monografias, dissertações e teses, mas alguns questionamentos podem estimulá-los nas clínicas e centros especializados, como:

1. Qual a frequência do herpes simples recorrente na região peribucal e intrabucal em pacientes ortodônticos? Qual a região mais comprometida pelas manifestações clínicas?

2. Qual o momento em que o diagnóstico é mais frequentemente realizado: nos primeiros atendimentos relacionados ao planejamento e instalação dos aparelhos ortodônticos ou nas sessões de tratamento e conclusão?

3. Quantos pacientes apresentam herpes simples recorrente na clínica ortodôntica e qual a possibilidade de transmissão de paciente para paciente nos atendimentos realizados?

4. Quantas pessoas que trabalham na clínica (atendentes, auxiliares, estagiários e profissionais) apresentam manifestações clínicas de herpes simples recorrente? Essas determinações, quando realizadas, devem ter como parâmetro-controle um grupo populacional não envolvido com atendimento clínico, como, por exemplo, pessoas envolvidas em atividades administrativas de empresas não-odontológicas.

5. Dessas manifestações clínicas, quantas são na região peribucal e intrabucal e quantas são em outros locais, como nas mãos, dedos, olhos, face e outras mucosas? Há uma preocupação em detectar o 
herpes simples recorrente ocupacional?

6. Na ficha clínica e no atendimento dos pacientes, existe uma preocupação especial com a doença? Os profissionais da área estão preparados para reconhecer as lesões na mucosa bucal e pele peribucal?

\section{REFERÊNCIAS}

1. ARDUINO, P. G.; PORTER, S. R. Herpes simplex virus type 1 infection: overview on relevant clinico-pathological features. J. Oral Pathol. Med., Copenhagen, v. 37, p. 107-121, 2008.

2. ARDUINO, P. G.; PORTER, S. R. Oral and perioral herpes simplex virus type 1 (HSV-1) infection: review of its management. Oral Dis., Copenhagen, v. 12, p. 254-270, 2006

3. BUDDINGH, G. J. et al. Studies of the natural history of herpes simplex infections. Pediatric, Springfield, v. 11, p. 595-612, 1953.

4. CONSOLARO, A.; VASCONCELOS, M. H. F. Etiopatogenia do herpes simples: uma revisão. Estomatol. Cult., Bauru, v. 14, n. 1/2, p. 68-73, 1984.

5. COREY, L.; SPEAR, P. G. Infections with herpes simplex viruses N. Engl. J. Med., Boston, v. 314, p. 686-691, 749-757, 1986.

6. COWDRY, E. V. The problem of intranuclear inclusions in virus diseases. Arch. Pathol., Chicago, v. 18, p. 527-542, 1934.

7. DOUGLAS JR., R. G.; COUCH, R. B. A prospective study of chronic herpessimplex virus infection and recurrent herpes labialis in humans. J. Immunol., Baltimore, v. 104, p. 289-302, 1970.

8. FATAHZADEH, M.; SCHWARTZ, R. A. Human herpes simplex infections: epidemiology, pathogenesis, symptomatology, diagnosis and management. Clin. Exp. Dermatol., Oxford, v. 32, no. 5, p. 625-630, Nov. 2007.

9. FATAHZADEH, M.; SCHWARTZ, R. A. Human herpes simplex labialis. J. Amer. Acad. Dermatol., St. Louis, v. 57, p. 737-763, 2007.

10. GILBERT, S. et al. An update on short-course intermittent and prevention therapies for herpes labialis. Herpes, Worthing, v. 4, p. 13-18A, 2007. Supplement 1.

11. GRUNEWALD, K. et al. Three-dimensional structure of herpes simplex virus from cryo-electron tomography. Science, Washington, D. C., v. 302, p. 1396-1398, 2003.

12. LAZAR, M. P. Vaccination for recurrent herpes simplex infection; initiation of a new disease site following the use of unmodified material containing live virus. Arch. Dermatol., Chicago, v. 72 p. 70-71, 1956.

13. LEO, J. The new scarlet letter. Time, New York, v. 31, p. 34-38, 1982.

14. LUPPI, O. Herpes simples. An. Bras. Dermatol., Rio de Janeiro, v. 75, n. 3, p. 261-275, maio/jun. 2000.
Felizmente, a maior parte das pessoas jovens, nos dias atuais, passa ou passou por uma avaliação ou tratamento ortodôntico. Isso aumenta a responsabilidade do profissional com a biossegurança dos seus pacientes, de si mesmo e de sua família, colegas e auxiliares.
15. LUPPI, O.; SEMENOVITCH, I.; PEREIRA JÚNIOR, A. C. Epidemiologia dos herpesvírus. In: LUPPI, O.; SILVA, A. G.; PEREIRA JÚNIOR, A. C. Herpes: clínica, diagnóstico e tratamento. Rio de Janeiro: Medsi, 2000. p. 15-32.

16. MELL, H. K. Management of oral and genital herpes in the emergency department. Emerg. Med. Clin. North Amer., Philadelphia, v. 26, p. 457-473, 2008.

17. MILLER, C. S.; DANAHER, R. J. Asymptomatic shedding of herpes simplex virus (HSV) in the oral cavity. Oral Surg. Oral Med. Oral Pathol. Oral Radiol. Endod., St. Louis, v. 105, no. 1, p. 43-50, Jan 2008.

18. NAHMIAS, A. J.; ROIZMAN, B. Infection with herpes simplex viruses. N. Engl. J. Med., Boston, v. 289, no. 781-789, 1973.

19. SIEGEL, M. A. Diagnosis and management of recurrent herpes simplex infections. J. Amer. Dent. Assoc., Chicago, v. 133, p. 1245-1249, Sept. 2002.

20. SMITH, I. W.; PENTHERER, J. F. The incidence of herpesviruses hominis antibody in the population. J. Hyg., London, v. 65, p. 395-408, 1967.

21. STOCK, C. et al. Risk factors of herpes simplex type 1 (HSV-1) infection and lifestyle factors associated with HSV-1 manifestations. Eur. J. Epidemiol., Rome, v. 17, p. 885-890, 2001.

22. WALD, A. Subclinical shedding of herpes simplex virus in the genital tract: implications for transmission. Herpes, Worthing, v. 4, no. 2, p. 30-35, 1997.

23. WENTHWORTH, B. B.; ALEXANDER, E. R. Seroepidemiology of infections due to members of the herpesvirus group. Amer. J. Epidemiol., Baltimore, v. 94, p. 496-507, 1971.

24. WHITLEY, R. J.; ROIZMAN, B. Herpes simplex virus infection. Lancet, London, v. 357, p. 1513-1518, 2001.
Endereço para correspondência

Alberto Consolaro

E-mail: consolaro@uol.com.br 